\title{
The Spiritual Ballast of Qing Scholars in Classical Gardens Based on Six Chapters of a Floating Life
}

\author{
Xiao Lei \\ South China University of Technology, Guangzhou, China \\ Email:xwhcclxl@qq.com
}

How to cite this paper: Lei, X. (2017) The Spiritual Ballast of Qing Scholars in Classical Gardens Based on Six Chapters of a Floating Life. Open Journal of Social Sciences, 5, 234-240.

https://doi.org/10.4236/jss.2017.510020

Received: September 19, 2017

Accepted: October 28, 2017

Published: October 31, 2017

Copyright $\odot 2017$ by author and Scientific Research Publishing Inc. This work is licensed under the Creative Commons Attribution International License (CC BY 4.0).

http://creativecommons.org/licenses/by/4.0/

\section{(c) (i) Open Access}

\begin{abstract}
Ancient Chinese scholars considered the nature as the philosophical proposition of life's reflective objects and applied it in life. The passions of human (pleasure, anger, sorrow and joy) often come from the natural landscapes. Lao-Zhuang philosophy proposed the philosophical view of advocating the nature and laid the natural landscape garden culture foundation. Meanwhile, this acts on the landscapes of scholars. Chinese paintings and classical garden culture are important constituent parts in traditional Chinese culture. Both of them have a close relation. The former has the spiritual pursuit beyond the world, while the latter endows spirit with entity, hoping for being a hermit in the world. Beginning with theory of paintings, garden appreciation and garden interest shown in Six Chapters of a Floating Life, the author studied Shen $\mathrm{Fu}$ and his wife's comprehension on paintings, their contact details with scholars in the same era, as well as life interest and life attitude in gardens, trying to understand spiritual ballast of Qing scholars displayed in classical gardens through small ones.
\end{abstract}

\section{Keywords}

Classical Garden, Scholar Landscape, Six Chapters of a Floating Life, Spiritual Ballast

\section{Six Chapters of a Floating Life and Qing Scholars}

Qing scholars were filled with contradictions. On the one hand, they wanted to get rid of the traditional constraint, pursued for individual liberation, and got the personal independence and behave with dignity. On the other hand, they were wrapped by tradition and couldn't get out of the orthodox with imperial 
examinations. Mentally, they could exceed the reality or be a hermit, escaping in landscapes, but they still placed themselves in the shadow of the era in actual life and couldn't escape from it. As a result, they abandoned themselves to nature in paintings and gardens and looked for spiritual ballast.

Six Chapters of a Floating Life is a miracle in ancient Chinese prose creation. It is a "perfect" autobiographical prose, showing big-hearted and free emotions and holding the strong affection of ancient Chinese scholars. Particularly, all of these are reflected in the unique aesthetic taste, satisfaction in poverty and spirituality and leisurely and carefree mood. In Six Chapters of a Floating Life, we can find out the relationship between the spiritual ballast of Qing scholars and the classical garden.

\section{Theory of Paintings and Spiritual World in Six Chapters of a Floating Life}

Six Chapters of a Floating Life described life of Shen Fu and Chen Yun. Their life was artistic and literary. In daily life, they constantly showed their opinions on poems, paintings and articles. This was closely related to Shen Fu's life. This was his profound accumulation on artistic appreciation, including poems, articles and paintings, so as to naturally reveal in daily life. This was the life interest of ancient Chinese scholars and also the special lifestyle for scholars. In the section, the author focused on discussing influences of traditional Chinese paintings on Chinese scholars in Qing Dynasty, represented by Shen Fu, especially for influences on garden aesthetics and garden interest.

Under the guidance of characteristic painters who had different painting styles, Shen Fu's paintings were as open, diversified and all-inclusive as his articles; these could be used by him. Moreover, he also had the good control for the artistic conception skills for landscape paintings. Meanwhile, he also showed ancient Chinese scholars' yearning and pursuit for the nature. After that, in addition to screen, paintings also occupied the large space in Shen Fu's life. In 1800, Shen Fu once painted a painting named Wuyin Nunnery Picture to give it to Monk Zhuyi who visited Laie Temple in Xishan of Suzhou. In 1803, after Chen Yun passed away, Shen Fu made a living by selling paintings in Yangzhou. In 1804, Shen $\mathrm{Fu}$ "drew a picture with monks" in the Great Mercy Storied-Pavilion of Xixiao Temple [1]. In 1805, Shen Fu painted Mountain Wind Figure of Fushan of 12 Volumes in Snowsea Merlin of the Dengwei Mountain in Suzhou for Xia Jieshi. During Daoguang period, Shen Fu painted the Shuihui Garden Figure for Mao Qingshi [2]. The figure now is collected in Shanghai Museum. The figure's picture was published in the title page of Six Chapters of a Floating Life translated by Lin Yutang (Figure 1).

It can be observed from the figure that Shen Fu's landscape paintings had high attainments, show the style of masters. From the judgment of Chen Yupi, Shen Fu's "paintings in his middle age got close to Ni Zan, and painting style was elegant". The old saying goes, "if we want to know about a person, we must know 


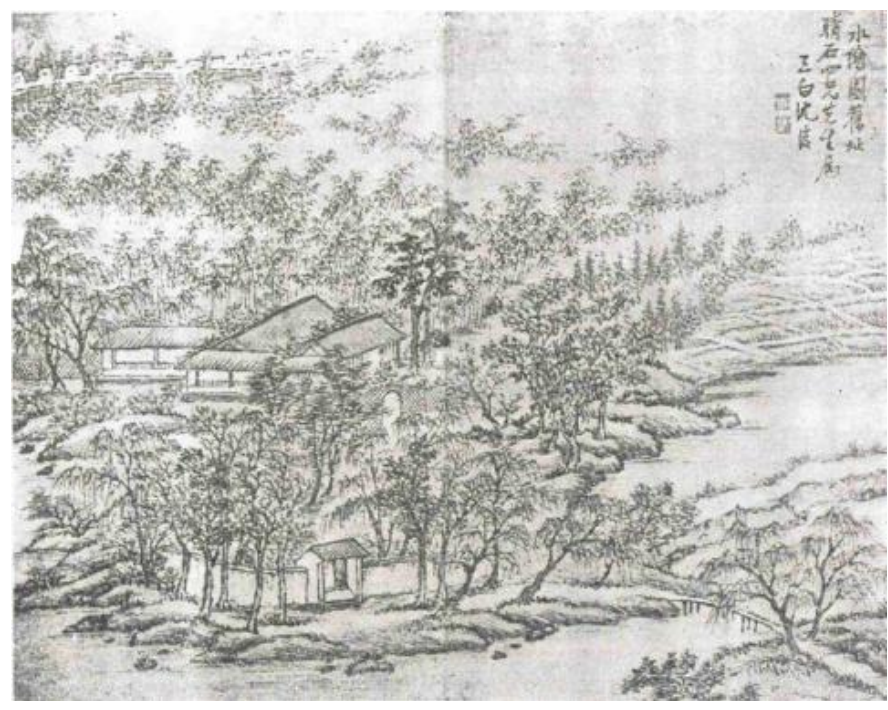

Figure 1. Shuihui Garden figure.

about their friends. From the perspective of Shen Fu's friends (Lu Zhang, Yang Changxu, Yuan Shaoqian, and Wang Yan), paintings of these scholars were as elegant and self-admired as their behaviors. Yang Bufan (Changxu) was good at figure portraits. Xiao Shaoyu (Pei) was proficient in landscape paintings. Wang Xinglan (Yan) was skilled in flowers and feathers" [3].

It can be observed from Shen Fu's paintings and friends' works that ancient Chinese scholars often regarded the nature as the philosophical proposition for life's reflective objects and applied it in life. The passions of human (pleasure, anger, sorrow and joy) often came from landscapes. Laozi used his cognition on landscapes to explore the secret in the universe and review the numerous phenomenon of social life, showing "man follows the earth, the earth follows the world, the world follows Dao way and the Tao way follows the nature." The origin principle of all living things showed that the "nature" is the ubiquitous and eternal proposition and proposed the philosophical view of advocating the nature. Zhuangzi further developed the philosophical concept, showing that only man abides by the natural disciplines can they achieve their purpose. He advocated "letting things slide" and obtained the concept of "natural beauty in the world". That is to say, "great wisdom appears stupid" or "no engraving" shows the natural beauty without artifact. Laozi and Zhuangzi laid the cultural foundation on natural landscapes and acted on the landscape paintings of scholars. The description about landscape paintings in Six Chapters of a Floating Life came from scholars' yearning for the nature and pursuit for the refined spiritual state, showing Qing scholars' spiritual pursuit for gardens' cultural value and aesthetics in Qing Dynasty.

\section{Classical Garden in Six Chapters of a Floating Life}

Landscape is the personalized nature and solidification for regional cultural psychology. The building and appreciation on gardens show the era, territory, 
culture and personal aesthetic style of building designers. In a sense, the garden was a means for ancient Chinese scholars to maintain relatively independent personality under the feudal autocracy. Qing Dynasty was the brilliant period for Chinese scholars' garden development. Scholars integrated personal emotions in the small world of gardens as many as possible. In scholars' gardens, there were filled as "pursuit", "sincerity", "proud" and "honesty" all around, showing the perfection of personality. Ancient Chinese scholars often used landscape gardens, plum blossoms, orchid, bamboo and chrysanthemum to express their thought, aspiration and diversified joy of life. For this reason, many scholars became the experts of garden architecture and garden appreciation. Lots of them have left articles about garden architecture and appreciation. Shen Fu not only appreciated aesthetics of gardens, but also had the unique opinions on garden construction and design. To some extent, his award opinions on gardens were filled with originality.

Appreciation standard of Shen Fu focused on the "nature". Nature was the aesthetic ideal for ancient scholars. Any artificial things might be inferior to natural perfection, no matter how exquisite and excellent it is. Laozi advocated "Dao way follows the nature". "Holding simplicity shows less selfishness and fewer desires." Zhuangzi advocated "following nature and value" and "beautiful followers", which has affected the aesthetic consciousness and artistic development for later generations. Li Bai said, "out of clear water lotus and nature without gingerbread", showing that the highest aesthetic realm means to exceed the beauty of nature. In other words, great wisdom appears stupid and a man of great wisdom appears slow-witted. Nature is the requirements of China for landscape art. The famous garden artist Mr. Chen Congzhou said, Chinese landscapes are composed of buildings, landscapes, flowers and trees, showing the idyllic and scenery for rockery design to achieve the realm that "it is artificial, but it seems that it is natural" [4].

In addition to nature, Shen Fu's appreciation on gardens also strived for "potential". If there is no potential in landscape gardens, they are boring. The so-called garden potential means that gardens must have some spiritual purport, including idea and finance of garden makers. Scholars appreciated elegant and original gardens. Once the garden is available for common people, it must be vulgar and disgusted. Just like Shen Fu treated "Fragrance Collecting Path" as "becoming vulgar". Qian Yong also mentioned the theory of elegance and vulgarity in Lvyuan Conghua. In these scholars' opinions, gardens were the places for spiritual comfort, but ordinary persons and laymen could enjoy it.

"Garden making is similar to write a poem, showing the zigzag process. With echo, piling up and mixing are forbidden. This can be called as the excellent structure. Thus, the garden can be constructed. Meanwhile, it must be matched with the master. Position should be suitable. Ordinary people shouldn't often stop here, thus the garden is called as a famous one. Nowadays, Town God's Temple in Changshu, Wujiang, Kunshan, Jiading, Shanghai and Wuxi has a 
garden pavilion and it is also original. In the season of spring and autumn, village women were crazy and cheer up for playing and singing, but whether it can be called as the so-called famous garden?" [5] Shen Fu's evaluation on landscapes not only was affected by ancient Chinese scholars on expressing ideal and cultivated their taste, showing his overall comprehension and appreciation for landscape art.

Here, it could be clearly shown that the garden is a means to maintain relative independence of personality by ancient Chinese scholars under the feudal autocracy system. Scholars could integrate with personal emotions in the small world. Garden making is similar to paintings. All of them pursue for the nature, but the difference lies in the different scales.

\section{Spiritual World of Shen Fu in Six Chapters of a Floating Life}

Edified by Lao-zhuang philosophy, Shen Fu advocated the nature and liked visiting well-known mountains and rivers. Gardens exactly could meet such a demand of scholars. As a result, many private gardens could provide an important site for group literary activity of scholars in regions south of the Yangtze River. As the maturity of cauliflowers, Shen Fu visited South Garden with his friends, "showing disorder cups and dishes. Everyone was happy. Some of them sat or lied or sang or howled" [6]. In Xiaoshuang Tower, Shenfu tested poems and learned paintings with Lu Zhang, Yang Bufan and Wang Yan, showing such a meaning. Shen Fu and his wife lived in Xiaoshuang Tower by Lu Zhang. Shen Fu "learned paintings, wrote cursive script and engraving seal" [7]. He always discussed poetry or paintings with friends to show different styles. "Taking plain paper on the wall forms Lan shadow and shade it with Chinese ink." Moreover, different people' have their own inscription [8], but they pursued for beauty, yearn for freedom, discussed "poetry and painting tastes, and highly discussed affairs. For contact between friends, Shen Fu proposed 'four taboos' and 'four acceptances'. 'Four taboos': official promotion, current affairs in distinct inn", eight-legged essay of eight-part essay, and performance for playing. Four acceptances were shown as follows: generosity, gracefulness, unrestraint and silence. "Four taboos" and "four acceptances" were just the portrayal of Shen Fu's life personality. In Xiaoshuang Tower, Shen Fu finally got rid of baseness and hypocrisy in officialdom and finally lived an unconstrained happy life with an easy grace.

In terms of Shen $\mathrm{Fu}$, to design potting and vase and develop his imagination in potting was the end result of his idyllic life. He placed potting under the "eave and appraised with Yun: a waterside pavilion should be established here, a thatched pavilion should be set here. Six characters 'between utterly routed' should be chiseled here. This is suitable for living or fishing or surveying at a distance. With a mind's intricate thoughts, it will be suitable for migrants." His appreciation and rejection or acceptance for gardens can embody a mood of es- 
tablishing a visitable and livable garden and a wish that his soul finally got a place for resistance. Shen Fu's garden appreciation not only pursued for nature, but also advocated the simplicity and seclusion under the large range of nature.

Seclusion interest and landscape hobbies are two sides of psychology. Looking for mountains and rivers is a dynamic pursuit, while living in seclusion is a static pursuit, which has been chased by Shen Fu and Chen Yun, when they spent a holiday at a summer resort in an old woman's home in their early years. At that time, "she planned to establish a house here and purchased $10 \mathrm{mu}$ garden around the house to train old man and plant fruits and vegetables for making a living, Shen Fu would paint, while I would do the embroidery for wines. With common vegetable rice, we would be happy for our lifelong and we wouldn't travel faraway." Shen Fu showed that "he clearly knew about it." The simple garden style and visitable and livable style made Shen Fu yearning for it. Such a garden made many scholars yearning and pursue for it. Just like Li Yu said, "happiness comes from inner heart. If you feel happy from your heart, everything is enjoyable."

Numerous scholars balanced their psychology in the dream of such gardens and fulfilledtheir ideal. Shen Fu's interest in upholding simplicity and seclusion was not only limited by material conditions of poverty, but also included an important cause-accumulation of traditional Chinese art spirit for advocating nature. Beginning with Laozi and Zhuangzi, Chinese art tried to advocate mutual beauty of the nature. Under the circumstance, we found that spiritual pursuit and bailment of scholars in Qing Dynasty obtained in theory of paintings would be appeared here. Yearning for the nature and pursuit for refined spiritual state also embody gardens' cultural value of Qing scholars and their spiritual pursuit for aesthetics.

\section{Qing Scholars' Spiritual Ballast in Classical Gardens from the Perspective of Six Chapters of a Floating Life}

Shen Fu's Six Chapters of a Floating Life is an autobiographical novel. Though Shen Fu always emphasized on "recording truth and practical work", Shen Fu's Six Chapters of a Floating Life might be a small world constructed by Shen Fu and the "artwork to cover up artwork itself" according to the statement of Yuwen Suo'an. He exactly achieved his dream in the elaborative small world. He imaged his garden in potting and looked forward to his life in the imaginary graden. This might be a dream with mystery of mysteries. Qing scholars enjoyed sense of sureness from visiting and appreciating gardens to close to the nature. The idea of the theory that man is an integral part of nature would be satisfied. For some scholars, gardens and their families would be the residences after the felt lost in the society. Their political status might be kept in the ruled status. They assumed the culture, while culture endowed them with independence, subjectivity and surpassing consciousness. As a result, their suppression on monarchical power might be more sensitive to common people. In this way, they 
might have the profound feeling on self-spirit. The personal structure of scholars was composed of spiritual self-rescue and social rescue, thus they were easily to absorb Taoism under the specific social conditions and personal situations, so as to trigger the self-rescue consciousness in their heart. Similarly, scholars that pursue Taoism theory will have the strong rescue wish under the specific situations. In other words, advance and retreat, official and hermit, self-rescue and social rescue were mingled in every scholar at every time. Gardens were equivalent to the buffer zone for scholars' advancing and retreating, which might be available in both directions. These scholars could spend their lifelong with tall bamboos and books. That is to say, "they edify their spirit with bamboos; spend a whole day with firewood and fishing gear; chant with poems, showing unconstraint and leisure in his lifelong". In Six Chapters of a Floating Life, Shi Yunyu once named "Unconstrained Boat" of Shen Fu as yachting in the word and traveling around with unconstraint.

These leisurely and carefree moods in the book embody the author's uninhibited attitude. This is connected with the freer and more liberated secluded scholars' spirit in spirit and secular morality. To sum up, Six Chapters of a Floating Life embodies the seclusion thought of ancient Chinese scholars. Superficially, they secluded in the countryside and landscape, but they actually secluded in mundane, adhering to philosophy of Laozi and Zhuangzi. "Greatest genius often lies concealed". They gave all spiritual ballast in gardens, surpassing the world and hiding. This was the masqueraded means of Shen Fu in reality of middle term of Qing Dynasty. He was also the representative of numerous substrate scholars' seclusion by virtue of gardens.

\section{References}

[1] Shen, F. (2000) Six Chapters of a Floating Life, Shanghai Ancient Book Publishing House, Shanghai, 21.

[2] Jiang, B.L. (1940) Molin Events Vol. 6, Treasure Imitated Sung Character Refined Cersion of Zhonghua Book Company, Beijing.

[3] Chen, Y.P. (1996) Shen Sanbai and His Six Chapters of a Floating Life. Da'an Publishing Press, Zigong, 37.

[4] Jiang, W.L. (1995) Four Events about the Author Shen Fu's Six Chapters of a Floating Life. Journal of Shantou University, 1, 37.

[5] Chen, C.Z. (1984) Shuo Yaun. Bibliography and Document Publishing House, hanghai, 6, 2 .

[6] Qian, Y. (1979) "Landscape" and "Garden Making": The historical notes in Qing Dynasty. Zhonghua Book Company, 20, 545

[7] Li, Y.( 2000) Leisure Recording Easy Life. Shanghai Ancient Book Publishing Press, Shanghai, 340 .

[8] Yuwen, S. (2004) Memory-The Past Reappearance in Chinese Classical Literature. Sanlian Bookstore, Beijing, 117 